\title{
Curing Efficacy of LED and QTH Light Curing Units for Curing Nanocomposite Resins - A Systematic Review
}

\author{
Dr.Nishad.N.T ${ }^{1}$, Dr.Sujeer.R ${ }^{2}$, Dr.Toby Thomas ${ }^{3}$, Dr.Veronica. ${ }^{4}$ \\ 1,2,3\&4 (Dept. Conservative Dentistry \& Endodontoics, Saveetha Dental College \& University, Chennai, India)
}

\begin{abstract}
:
Background: In adequate polymerization of composite resins has been associated with loss of biocompatibility, retention loss, breakage, excessive wear, and restoration softness. The aim of this systematic review was to evaluate the curing depth and surface microhardness of nanocomposite resin cured with LED and QTH Light curing units.

Search Strategy: An electronic search was conducted of the PubMed, MEDLINE and MeSH data bases from 1994 to 20th July 2012. Hand searching included relevant journals and bibliographies of all relevant papers and review articles from 1994 to 2012.

Main Results: Three studies compared curing depth of nanocomposites cured by LED and QTH. Out of which two showed significant increase in curing depth for LED and One study showed no significant difference. Eight studies compared the surface microhardness out of which three showed significant increase in surface microhardness of nanocomposites cured with LED, one study showed significant increase for nanocompsite cured with QTH and four articles showed no significant difference in microhardness between LED and QTH.

Conclusion: LED light curing units offers equal or better performance for curing nanocomposite resins as compared to QTH light curing units.
\end{abstract}

Key Words: Nanocomposite, LED, QTH, Curing efficacy

\section{Introduction}

The use of light-activated resin composites in restorative dentistry has grown dramatically in recent years. There are currently a range of photo-polymerization techniques which have advantages and disadvantages with respect to the properties of the final restoration and of the long-term status of the restored teeth. Inadequate polymerization has been associated with loss of biocompatibility, color change, retention loss, breakage, excessive wear, and restoration softness. Many visible light-activated composite resins use diketone photoinitiators such as camphorquinone. The relationship between the spectral distribution of the output from the light curing sources and the maximum absorption of the photoinitiator is expected to have effects on the physical properties of the cured composite.

Different factors related to the composition may affect the mechanical properties of the material, such as the type and concentration of the monomer that is used or the size, type, and quantity of the filler that is present in the material[1]. Therefore nano particles were inserted into composites in order to enhance their mechanical properties and to promote greater esthetic value to the restorations performed with these materials [2] as well as to increase packing of fillers and thus reduce polymerization shrinkage.

Quartz-tungsten halogen (QTH) and light-emitting diode (LED) are the most popular light sources that are used to cure dental resins. The QTH presents a broad wavelength spectrum, which allows efficient activation of different photo-initiators that are used as an alternative to camphorquinone, the most common initiator among light curing dental resins [3].

In comparison to QTH devices, LEDs have a superior life span which does not compromise their light intensity after lengthy use. Nevertheless, the LEDs have a narrow wavelength spectrum, which may inadequately cure composite resins that contain alternative initiators (monoacrylphosphine oxide or TPO-390 $\mathrm{nm}$ and phenylpropadione, or PPD-410nm), due to the different wavelength that these photo-initiators require[4].

Curing depth and surface micro hardness evaluation are the widely used parameters for assessing the composite curing and the efficiency of light sources. Even though reviews are published on curing effectiveness of light curing units there is no systematic review published yet in the literature on curing efficacy of light curing units on nano composite resins.

\subsection{Aim}

The aim of this systematic review was to evaluate the curing depth and surface microhardness of nanocomposite resin cured with LED and QTH Light curing units. 


\subsection{Structured Question}

Whether there is any difference in curing depth and surface micro hardness of nanocomposite resin cured using LED and QTH light curing units?

\section{Materials and Methods}

Sources Used For identification of studies included or considered for this review, detailed search strategies were developed for the database searched. The MEDLINE search used the combination of controlled vocabulary and free text terms.

\subsection{Searched Databases}

- $\quad$ PubMed(January 1994 to July 2012)

- $\quad$ PubMed Advanced Search (January 1994 to July 2012)

- $\quad$ MEDLINE

\subsection{Language}

There were no language restrictions. Articles with translations of foreign language available were included to eliminate any possible language bias.

\subsection{Hand Searching}

- Journal of Operative Dentistry

- Dental material journal

- Dental Materials

- Journal of Contemporary Dental Practice

- Quintessence International

- Journal of Adhesive Dentistry

- Journal of Conservative Dentistry

- Journal of Esthetic and Restorative Dentistry

- Journal of American science

- Indian Journal of Dental Science

\subsection{Types of Studies}

In-vitro studies comparing depth of cure and surface microhardness of nanocomposite resin using LED and QTH Light curing units.

Composite resin Included: Nanocomposite resin

Type of Interventions: Light curing of composite resin blocks with specified dimensions cured using LED and QTH Light curing units.

Type of outcome: Depth of cure of composite measured using ISO:4049 scraping test5 and surface microhardness measured using universal testing machine.

\subsection{Inclusion Criteria}

The title, keywords and abstracts of reports identified from electronic searching for evidence of following criteria were examined:

- Studies done on nanocomposite resins,

- Studies done in which curing done using LED and QTH Light curing units

- Studies which evaluated depth of cure using ISO 4049 Scraping test

- Studies performed in which surface micro hardness is evaluated using universal testing machine.

\subsection{Exclusion Criteria}

Papers were excluded when they were:

- Studies done on other composite resins

- Studies not using LED curing light units

- Studies not using QTH light curing units,

- Studies not using either depth of cure or surface micro hardness for evaluating curing efficacy

- Review articles 
Table. 1 Variables of Interest

\begin{tabular}{|l|l|}
\hline 1 & depth of cure \\
\hline 2 & Surface microhardness \\
\hline
\end{tabular}

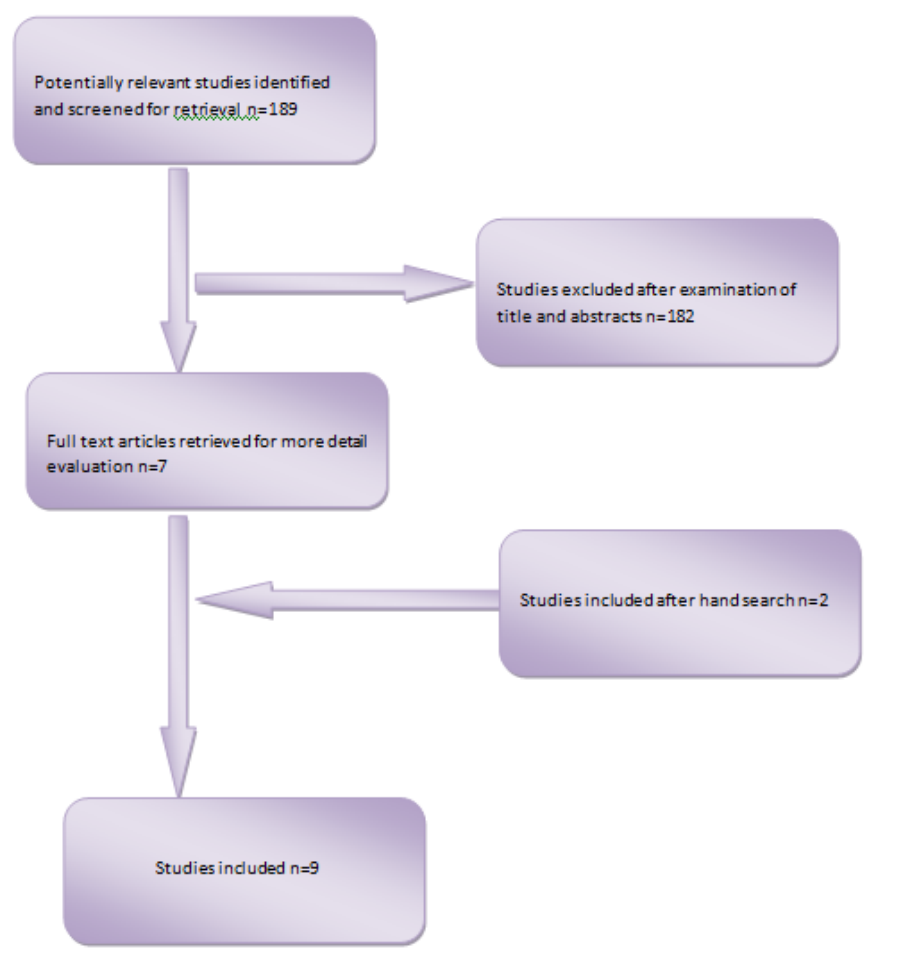

Figure.1 Search flow chart

\subsection{Description of Studies}

\section{Results}

The search identified 189 publications out of which 182 were excluded after reviewing the title and abstract. 2 articles included after hand search. Full articles were obtained for 9 studies. None of these publications were excluded further. Therefore a total of 9 publications fulfilled all criteria for inclusion.

Table.2 General Information Of Selected Articles

\begin{tabular}{|c|c|c|c|c|c|}
\hline $\begin{array}{l}\text { S. } \\
\text { NO }\end{array}$ & AUTHOR \& YEAR & JOURNAL NAME & $\begin{array}{l}\text { SAMPLE } \\
\text { SIZE } \\
\end{array}$ & CURING LIGHTS USED & $\begin{array}{l}\text { VARIABLE } \\
\text { EVALUATED } \\
\end{array}$ \\
\hline 1 & $\begin{array}{l}\text { Adriano Fonseca } \\
\text { lima et al } 2012\end{array}$ & Eur J Dent & 10 & LEDand QTH & Surface Hardness \\
\hline 2 & $\begin{array}{l}\text { Sahar A M et al } \\
2012\end{array}$ & $\begin{array}{l}\text { Journal of American } \\
\text { science }\end{array}$ & 32 & $\begin{array}{l}\text { LED-BluephaseC5 QTH- } \\
\text { Cromalux7050 }\end{array}$ & Surface Hardness \\
\hline 3 & $\begin{array}{l}\text { Batu Can Yaman et } \\
\text { al } 2011\end{array}$ & $\begin{array}{l}\text { Journal of } \\
\text { Conservative } \\
\text { Dentistry }\end{array}$ & 40 & $\begin{array}{l}\text { LED-Elipar } \\
\text {-Smart lite } \\
\text { QTH-VIP } \\
\text {-Hiluxplus } \\
\end{array}$ & $\begin{array}{l}\text { Depth of Cure } \\
\text { \&Surface Hardness }\end{array}$ \\
\hline 4 & $\begin{array}{l}\text { Adam kuzgoz et al } \\
2011\end{array}$ & $\mathrm{~J}$ Esthet Restor Dent & 8 & $\begin{array}{l}\text { LED-Elipar freelight2 } \\
\text { QTH-Astralis }\end{array}$ & $\begin{array}{l}\text { Depth of Cure } \\
\text { \&Surface Hardness }\end{array}$ \\
\hline 5 & $\begin{array}{l}\text { S M Marchan et al } \\
2011\end{array}$ & Operative Dentistry & 5 & $\begin{array}{l}\text { LED-Elipar freelight2 } \\
\text { QTH-Biolite } 210\end{array}$ & Surface Hardness \\
\hline 6 & $\begin{array}{l}\text { Luis Gustavo et al } \\
2011\end{array}$ & Braz Oral Res & 10 & $\begin{array}{l}\text { LED-Radii } \\
\text { QTH-Optilux }\end{array}$ & Surface Hardness \\
\hline 7 & $\begin{array}{l}\text { R B T Price et al } \\
2010\end{array}$ & Operative Dentistry & 5 & $\begin{array}{l}\text { LEDAllegro Bluphase16i } \\
\text { LEDemetron, Smart lite } \\
\text { Ultralume QTH- Optilux }\end{array}$ & Surface Hardness \\
\hline 8 & $\begin{array}{l}\text { Ruchi Dhir Sharma } \\
\text { et al2009 }\end{array}$ & $\begin{array}{l}\text { Indian Journal of } \\
\text { Dental Sciences. }\end{array}$ & 10 & $\begin{array}{l}\text { LED-Lite XTM } \\
\text { QTH-Qlux }\end{array}$ & Depth of Cure \\
\hline 9 & $\begin{array}{l}\text { Habbzoglu et al } \\
2007\end{array}$ & $\begin{array}{l}\text { Dental Materials } \\
\text { Journal }\end{array}$ & 10 & $\begin{array}{l}\text { LED-Ultra lite } \\
\text { QTH-Heliolux } \\
\text { PlasmaArc-Apollo95 }\end{array}$ & Surface Hardness \\
\hline
\end{tabular}


Table3. Results

\begin{tabular}{|c|c|c|c|c|}
\hline $\begin{array}{l}\text { S. } \\
\text { NO }\end{array}$ & $\begin{array}{l}\text { AUTHOR \& } \\
\text { YEAR }\end{array}$ & $\begin{array}{l}\text { SAMPLE } \\
\text { SIZE }\end{array}$ & $\begin{array}{l}\text { VARIABLES } \\
\text { EVALUATED }\end{array}$ & OUTCOME \\
\hline 1 & $\begin{array}{l}\text { Adriano fonseca } \\
\text { lima et al } 2012\end{array}$ & 10 & Surface Hardness & $\begin{array}{l}\text { No significant difference } \\
\text { between the groups }\end{array}$ \\
\hline 2 & $\begin{array}{l}\text { Sahar A M et al } \\
2012\end{array}$ & 32 & Surface Hardness & $\begin{array}{l}\text { Significant increase for cured } \\
\text { with LED }\end{array}$ \\
\hline 3 & $\begin{array}{l}\text { Batu Can Yaman } \\
\text { et al } 2011\end{array}$ & 40 & $\begin{array}{l}\text { Depth of Cure \& } \\
\text { surface Hardness }\end{array}$ & $\begin{array}{l}\text { Significant difference } \\
\text { between the groups for both } \\
\text { depth of cure and micro } \\
\text { hardness }\end{array}$ \\
\hline 4 & $\begin{array}{l}\text { Adam kuzgoz et } \\
\text { al } 2011\end{array}$ & 8 & $\begin{array}{l}\text { Depth of Cure \& } \\
\text { Surface Hardness }\end{array}$ & $\begin{array}{l}\text { No significant difference } \\
\text { between the groups for depth } \\
\text { of cure . } \\
\text { Significant difference present } \\
\text { for top and bottom values of } \\
\text { microhardness. }\end{array}$ \\
\hline 5 & $\begin{array}{l}\text { S M Marchan et } \\
\text { al } 2011\end{array}$ & 5 & Surface Hardness & $\begin{array}{l}\text { No significant difference } \\
\text { between the groups }\end{array}$ \\
\hline 6 & $\begin{array}{l}\text { Luis Gustavo et } \\
\text { al } 2011\end{array}$ & 10 & Surface Hardness & $\begin{array}{l}\text { Significant difference } \\
\text { between groups for } \\
\text { microhardness }\end{array}$ \\
\hline 7 & $\begin{array}{l}\text { R B T Price et al } \\
2010\end{array}$ & 5 & Surface Hardness & $\begin{array}{l}\text { No significant difference } \\
\text { between the groups }\end{array}$ \\
\hline 8 & $\begin{array}{l}\text { Ruchi dhir } \\
\text { Sharma et } \\
\text { al2009 }\end{array}$ & 10 & Depth of Cure & $\begin{array}{l}\text { Significant difference } \\
\text { between the groups }\end{array}$ \\
\hline 9 & $\begin{array}{l}\text { Habbzoglu et al } \\
2007\end{array}$ & 10 & Surface Hardness & $\begin{array}{l}\text { No significant difference } \\
\text { between the groups }\end{array}$ \\
\hline
\end{tabular}

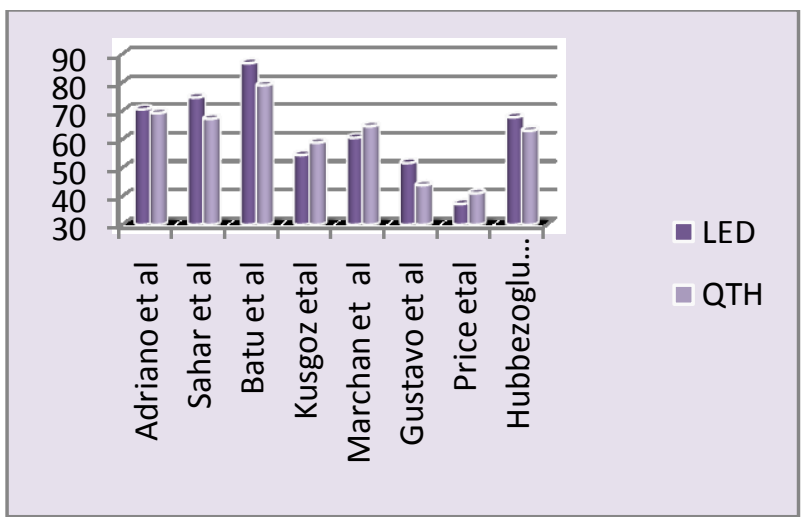

Figure.2 Bar Chart showing Mean Surface Microhardness Values of Nanocomposites given in selected articles



Figure3. Bar Chart showing Mean Depth of Cure Values of Nanocomposites given in selected Articles 


\section{Discussion}

A total of nine studies were included for the systematic review. Among the nine articles three articles compared the depth of cure of nano composite resins cured using LED and QTH Light curing units. Eight compared the surface microhardness of nanocomposites. Three of the articles compared Degree of conversion and one evaluated the microleakage.

Out of the nine included articles, seven used only one LED and one QTH Light curing lamps for curing the composite resin specimens. One article used two LED and two QTH. Another article used five different LED and one QTH light curing units for curing the composite resins. All the nine articles used nanocomposites out of which three articles evaluated hybrid composite also. Two articles evaluated five others along with nanocomposites. One study used three other composites along with nanofilled.

The variables of interest assessed in the systematic review are depth of cure and surface microhardness of nano composite resin cured using LED and QTH light curing units. All the studies included in this systematic review followed the criteria for specimen preparation, cylindrical specimens of specified dimensions. Light curing done from the top surface of prepared specimens and depth of cure assessed using ISO:4049 Scrape test [5] and surface microhardness evaluated using universal testing machine by placing three to five indentations by specified loads on the top and bottom surface of cured specimens. The mean value interpreted as microhardness value of the cured specimen.

\subsection{Interpretation of Results}

The literature reveals the in vitro studies for assessing the comparative evaluation of depth of cure and surface microhardness of nanocomposite resins cured using LED and QTH Light curing units.

An in vitro study done by Adriano Fonseca lima et al 2012 [6] evaluated the effects of different light sources and curing time on the degree of conversion and microhardness of two surfaces within a nanofilled composite resin. Four experimental groups $(\mathrm{n}=10)$ were formed in accordance with the light source quartztungsten halogen, or light emitting diode and the time of curing (20 s or $40 \mathrm{~s}$ ). Knoop microhardness and degree of conversion was measured at the top and the base of the specimens. Both the degree of conversion and microhardness were higher at the top than at the bottom of the specimens. The QTH light source presented better values on the degree of conversion evaluation, but this result was not observed in the microhardness evaluation. Although forty seconds of curing promotes an increased level of microhardness,

This study reveals no significant difference surface micro hardness cured using LED and QTH light sources. It could be concluded that increasing the time of curing to $40 \mathrm{~s}$ promotes an increase in microhardness.

A study done by Sahar et al 2012[7] investigated the effect of remineralization and light exposure on microhardness of Nano-composite, Nano glass ionomer and Micro-hybrid composite. 96 samples were prepared and were divided according to materials used into three groups and then each group was subdivided into subgroup according to light of curing. Two curing units were used to polymerize the samples, QTH and LED. In all the tested materials, LED curing, whether used alone or in combination with remineralizing mouse, resulted in greater microhardness, at both the top and bottom surfaces, compared to halogen light curing alone or in combination with remineralizing mouse. Glass ionomer, whether cured by LED or halogen light-showed the lowest microhradness compared to Hybrid and Nanocomposite. This study reveals there is a significant increase in surface microhardness value of nanocomposite cured with LED when compared to QTH.

The in vitro study done by Batu Can Yaman et al 2011[8] compare the effects of two conventional halogen (Hilux Plus and VIP) and two LED (Elipar FreeLight 2 and Smart Lite) light curing units on the depth of cure and the microhardness of various esthetic restorative materials. The curing depth and microhardness of a compomer (Dyract Extra), a resin-modified glass ionomer (Vitremer), a packable composite (Sculpt It), an ormocer (Admira), a hybrid composite (Tetric Ceram), two microhybrid composites (Miris and Clearfil Photo Posterior) and, a nanofil composite (Filtek Supreme) were determined using a scraping method and a hardness tester. A total of 320 samples were prepared using the eight different materials $(n=10$ samples for each subgroup). The scraping test was based on ISO 4049:2000. Vicker's microhardness testing was carried out using hardness tester. Best microhardness results were obtained with the LED light curing units and Tetric EvoCeram and Filtek Supreme achieved the highest hardness values. The nanofil composite, Filtek Supreme, showed the best curing depth results in all the tested light curing systems. This study revealed significant increase in depth of cure and surface microhardness of nanocomposite cured with LED as compared to that cured with QTH.

A study published by Adam kuzgoz et al 2011[9] determine the depth of cure, degree of conversion hardness, and cervical sealing ability of silorane-based composite (Filtek Silorane) and to compare with methacrylate-based composites Filtek Supreme XT (Nanocomposite) and Filtek P60 (hybrid composite). The depth of cure was determined using the ISO 4049:2000 standard. Microleakage was evaluated by measuring dye penetration across the gingival wall in cross-sectioned specimens. Silorane showed lower depth of cure and surface microhardness than nanocomposie and hybrid composite. This study showed that there is significant 
increase in surface hardness of nanocomposite cured using QTH as compared to QTH but there is no significant difference in depth of cure of nancomposite cured with LED and QTH

An in vitro study done by S M Marchan et al 2011[10] to investigate effectiveness polymerization of various curing regimen on five nanocomposite materials Z350, Grandio, Clearfil Majesty Esthetic, Ice and Tetric EvoCeram by utilizing microhardness measurements. Five specimens of each material were subjected to one of three curing regimes: curing with a halogen light for 20 seconds, curing with an LED light for 20 seconds and curing with an LED light for 10 seconds. Immediately following curing, hardness measurements were made with a Vickers indenter at five different locations on both the top and bottom surfaces of each disc. The mean for each surface was calculated. Comparison of the top and bottom values of discs cured with the LED 10 second regime demonstrated significant differences. Grandio samples cured with the halogen 20 second regime showed no statistical differences between top and bottom microhardness values; however, the bottom values of Grandio discs cured with the LED 20 second and 10 second regimes were significantly lower when compared with top surface values . Clearfil Majesty Esthetic, Ice and Tetric Evo Ceram samples cured with the halogen 20 second regime produced significantly lower bottom microhardness values, while both LED regimes produced top and bottom surfaces that were statistically comparable. This study revealed that No significant difference in surface microhardness between nanocomposite cured using LED and QTH

A Study done by Luis Gustavo et al 2011 [11] The aim of this study was to evaluate the degree of conversion, surface micro microhardness and FT-Raman spectroscopy of one nanofilled and one microhybrid composite each with different opacities, namely enamel, dentin, and translucent, which were photo-activated by a quartz-tungsten-halogen lamp (QTH) and a light-emitting diode (LED) The microhybrid resin showed no differences in surface microhardness or FTIR values with different activation sources or opacity. The nanofilled dentin and enamel resins showed lower FTIR values than the translucent resin. The surface hardness values of the dentin shade of nanocomposites values varies significantly and were influenced by the light source. Comparing the mean values of study results it is shown that there is significant increase in microhardness of nanocomposite cured with LED compared with QTH.

An In vitro study performed by R B T Price et al 2010 [12] done hardness mapping technique to compare the ability of seven curing lights to polymerize five composites. Six curing lights (Sapphire [plasmaarc: PAC], Bluephase 16i [light emitting diode: LED], LEDemetron II [LED], SmartLite IQ [LED], Allegro [LED] and UltraLume-5 [Polywave LED]) were compared to an Optilux 501 (halogen: QTH) light. Five resin composites (Vit-1-escence, Tetric Evoceram, Filtek Z250, 4 Seasons and Solitaire 2) were polymerized at $4 \mathrm{~mm}$ and $8 \mathrm{~mm}$ from the end of the light guide. Four composites were light cured for the following times using these lights: Sapphire, Bluephase16i, LEDemetron II, SmartLite IQ, UltraLume-5, Allegro and Optilux 501. On each specimen, the surface microhardness was measured to determine the ability of each light to cure each brand of composites. The ability of the lights to cure these five composites was ranked from highest to lowest: Sapphire, Optilux 501, Allegro, UltraLume-5, SmartLite IQ, LEDemetron II and Bluephase 16i.This study showed no significant difference in mean values of suface microhardness between nanocomposite cured using LED and QTH.

A Study performed by Habbzoglu et al 2007 [13] examined the surface microhardness of four kinds of resin composites with different fillers and resin matrices. Ten specimens of $2 \mathrm{~mm}$ thickness and $4 \mathrm{~mm}$ diameter of each resin composite were polymerized using a halogen light, a blue light-emitted diode, and a plasma arc unit. Microhardness evaluation was performed at top and bottom surfaces for each specimen using a Vickers microhardness tester. Furthermore, morphologies of the polished top surfaces of composites cured with blue light-emitted diode were observed using scanning electron microscopy. Results indicated that composites cured with halogen or blue light-emitted diode light yielded higher microhardness values, although it also appeared to depend on the type of composite cured. Plasma arc curing according to manufacturer's instructions yielded the lowest microhardness values for all the materials. Among the materials tested, the nanofilled resin composite displayed the highest microhardness values for each curing regime. The study showed that there is no significant difference in microhardness of nanocomposite cured with QTH and LED.

An In vitro study performed by Ruchi Dhir Sharma et al 2009 [14] evaluated the effect of conventional Quartz Tungsten Halogen (QTH) curing unit and Blue Light Emitting Diode (LED) on degree of conversion of hybrid composite (Filtek Z250 3M ESPE) and nanocomposite (Filtek Z350, 3M ESPE) resins. 10 samples each were prepared according to restorative resin and light cure unit used- Hybrid/QTH, Nanocomposites/QTH, Hybrid/LED and Nanocomposites /LED. Degree of Conversion was measured by using Scraping method. Maximum degree of conversion was obtained for the Hybrid composites exposed both to LED and QTH. LEDs were found to cause greater degree of conversion than QTH in both the composites. The study revealed there is significant increase in depth of cure for nanocomposite cured with LED compared QTH 


\subsection{Defending the Results}

In vitro study done by Adriano fonseca lima et al 2012 [6] showed no significant difference surface micro hardness, cured using LED and QTH light sources. The degree of the conversion measurements was lower at the bottoms of the samples than at the top surface. This reduction probably occurred due to the decrease in the irradiance incident on the region. When the light emitted reaches the composite resin, all the specimens is irradiated. The light transmittance through the resin increment is reduced, influencing negatively the degree of conversion of the bottom of the increment. These results are similar to procedures where the indirect restorations compromise the degree of conversion of resin cement, due to the light attenuation through the restoration. The results of the microhardness test were somewhat similar to those of the degree of conversion evaluation. Reflecting the outcome of similar studies in each of the situations noted the top of the sample presents higher results than the bottom [15]. The results are probably due to the reduction in the light intensity on the region, similar the degree of conversion. Polymerization at reduced rate, as bottom of the specimen, may lead to a more linear polymer structure because relatively few growth centers are formed[16]. At a higher rate of polymerization, as top of the increment, caused by a higher power density, a multitude of growth centers are formed, leading to a more branched and cross linked polymer structure

Study done by Sahar et al 2012 [7] reveals there is a significant increase in surface microhardness value of nanocomposite cured with LED. As regards microhardness results from the current study were showed significant difference between top and bottom surfaces. This finding is in agreement with other studies that showed differences between top and bottom surface microhardness[17], alone or in combination with remineralizing mouse, resulted in greater microhardness, both at the top and bottom surfaces, compared to halogen light curing alone or in combination with remineralizing mouse. This may be due to higher light intensity of the newer LED devices with their narrow spectral output makes them even more efficient than conventional halogen light curing units $[18,19]$. This finding is in agreement with other studies that showed significant difference between the polymerization of composite resin with LED for 40s is better than that with Halogen light for 40 s cured group[20].

The In vitro study done by Batu can yaman et al 2011 [8] revealed significant increase in depth of cure and surface microhardness of nanocomposite cured with LED as compared to cured with QTH. Study hypothesis was that the two LED LCUs can have a better curing performance than halogen LCUs. In this study, the halogen lamps were found to exhibit irradiance near $460 \mathrm{~nm}$ and the LED LCUs at approximately $470 \mathrm{~nm}$, which better matches the most efficient wavelength for activation of the camphorquinone present in the resin. The scraping depth results can be explained by relating the emission wavelengths of the curing source to the absorption spectrum of camphorquinone, which has its peak absorption near $470 \mathrm{~nm}$. The curing depth depends on the penetration of the curing light into the composite [21]. It must be noted that the scraping depth results are dependent on the specific excitation peak of camphorquinone. Composites with initiator systems absorbing light in the visible range have been introduced. In addition to the standard visible light photoinitiator, camphorquinone, some manufacturers use a co-initiator that absorbs light at shorter wavelengths [22]

Study published by Adam kuzgoz et al 2011 [9] shown that there is significant increase in surface hardness of nanocomposite cured using QTH, but there is no significant difference in depth of cure of nancomposite cured with LED and QTH. Depth of cure depends on the monomer composition and type, light permeability of the filler and the concentration of initiator and accelerator and inhibitor in resin materials. Filtek silorane showed least curing depth followed by nano and hybrid composites. Nano filled composites are most difficult to cure because of their small filler particles cause light to scatter. Ratio of resin filler is also important. Higher the proportion of filler less will be the curing depth. Even though there is no significant difference the LED showed better result for curing depth as compared to halogen may be attributed to the difference in composition of composite which corresponds to iradiance range of different light curing units. Significant increase in microhardness value that cured with LED may also be attributed to the same reason.

In vitro study by S M Marchan et al 2011 [10] done to investigate effectiveness polymerisation of various curing regimen on five nanocomposite materials study revealed that no significant difference in surface microhardness of nanocomposite cured using LED and QTH. The interaction between the tip of light curing unit,shade of restorative material and interaction between different filler particles will affect the light transmittance properties through the thickness of the samples [23]. Grandio, the nano hybrid composite have the highest microhardness value of all the tested composites. This can be explained on the basis of increased filler loading present in the nano hybrid composites [24]. Presumably, there was high light scattering though the translucent resin because a higher transmittance of the light results in a higher Degree of conversion [25] which is strongly influenced by the resin opacity and filler contents [26]. For these reasons, composite resin with the dentin opacity needs to receive a higher exposure time to reach a similar DC of composite resin with enamel opacity

Study done by Luis Gustavo et al 2011 [11] aimed to evaluate the degree of conversion by surface micro microhardness and FT-Raman spectroscopy of one nanofilled and one microhybrid composite each with 
different opacities. The study showed that there is significant increase in microhardness of nanocomposite cured with LED. An increase in irradiance leads to a higher hardness in the composite resin. Polymerization depends not only on the intensity of the light, but also on the total amount transmitted throughout the polymer. Thus, one possible reason for this difference may be related to the energy density of the LED associated with the pigments of the resin composite that were able to scatter the light emitted from the QTH.

The In vitro study performed by Ruchi Dhir Sharma et al 2009 [13] evaluated the effect of conventional Quartz Tungsten Halogen (QTH) curing unit and Blue Light Emitting Diode (LED) on degree of conversion of hybrid composite and nanocomposite Showed significant increase in depth of cure for nanocomposite cured with LED compared QTH. Comparing the curing units, statistically no significant difference was observed for LED and QTH curing units in polymerizing hybrid Composites. However, regarding nanocomposites, LEDs were found to produce greater degree of conversion than QTH. Such a result can be attributed to narrow spectrum of LEDs which is more close to the absorption spectrum of photoinitiator (Camphorquinone) present in nanocomposite.

Study performed by Habbzoglu et al 2007 [14] examined the surface microhardness of four kinds of resin composites with different fillers and resin matrices showed that there is no significant difference in microhardness of nanocomposite cured with QTH and LED. LED light curing units has an emission spectrum similar to the absorption spectrum of CQ photoinitiator. This spectral homogeneity thus allows complete usage of the emitted light by LED light curing units, which otherwise does not happen with halogen or plasma arc curing [27]. It has been shown that blue light at different parts of the absorption spectrum of camphoroquinone produced different levels of curing efficiency and that light near the absorption peak was more effective in curing [2]

\subsection{Quality of Evidence}

Article referenced in this review are all In vitro studies, and hence categorized as level five. The level of evidence is low and because of this concern, extreme care was taken only to include articles which satisfy required protocol for quality - standardization of procedures, calibration of observers, accurate reporting of data and appropriate statistical analysis depending on distribution of data. Most of journals reviewed in this study were high impact factor journals.

Despite the fact that randomized clinical trials and clinical studies offer higher level of evidence, these studies are not yet published for assessing the curing efficacy of nano composites. As well as the parameters, surface microhardness and depth of cure cannot be assessed In vivo, further more they are difficult to standardize.

\subsection{Report Onoutliers Data}

Out of eight selected study comparing surface microhardness seven of the articles gives equal or better results for LED light curing units, only one article (Adam kuzgoz et al 2011) showed better surface microhardness value given by QTH as compared to LED. So it can be considered as outliers data.

\subsection{Inference}

From the available data the inferences obtained are Three studies compared curing depth of nanocomposites cured by LED and QTH Out of which two showed significant increase in curing depth for LED and one study showed no significant difference. Eight studies compared the surface microhardness out of which three showed significant increase in surface microhardness of nanocomposite cured with LED, one study showed significant increase for cured with QTH, four articles showed no significant difference in microhardness between LED and QTH.

\section{Conclusion}

With the limited evidence from the In vitro studies selected for the systematic review it can be concluded that, LED light curing units offers equal or better performance for curing nanocomposite resins as compared to QTH light curing units. The studies used for this systematic review are of low level of evidence (level 5). Long term studies evaluating clinical performance of nano composite resins cured with LED and QTH should be done to further validate the findings.

\section{References}

[1.] Lu H, Lee YK, Oguri M, Powers JM, Properties of a dental resin composite with a spherical inorganic filler, Oper Dent 31(6) 2006, 734-740.

[2.] Mitra SB, Wu D, Holmes BN, An application of nanotechnology in advanced dental materials, J Am Dent Assoc 134(10) 2003, $1382-1390$.

[3.] Cadenaro M, Antoniolli F, Codan B, Agee K, Tay FR, Dorigo Ede S, Pashley DH, Breschi L. Influence of different initiators on the degree of conversion of experimental adhesive blends in relation to their hydrophilicity and solvent content. Dent Mater 26(4) 2010, 288-294.

[4.] Jimenez-Planas A, Martin J, Abalos C, Llamas R, Developments in polymerization lamps, Quintessence Int39 (2) 2008, 74-84. 
[5.] International Organization for Standardization Dentistry -Polymer-based filling, restorative and luting materials. ISO 4049:2000, Geneve, 2000

[6.] Fonseca Lima1Kamila, Menezes Guedes de Andrade,Louise Esther da Cruz Alves, Giulliana Panfiglio Soares, Giselle Maria Marchi Flavio Henrique Baggio Aguiar, Alessandra Rezende Peris,Fabio Hiroyuki Ogata Mitsui.(2012) Influence of light source and extendedtime of curing on microhardness and degree of conversion of different regions of a nanofilled composite resins, Eur J Dent $6(2)$ 2012, 153-157

[7.] Sahar A. M. Abd El Halim, Effects of light curing and remineralization on micro hardness of nano esthetic restorative materials, Journal of American Science, 8(1) 2012, 147-151

[8.] Batu Can Yaman,Begium Guray Efes, Can Dorter Yavus,Sami Buyukgokcecu, The effects of halogen and light-emitting diode light curing on the depth of cure and surface microhardness of composite resins, J Conserv Dent 14(2) 2011, 136-139.

[9.] Kusgoz A, Ülker M, Yesilyurt C, Yoldas OH, Ozil M, Tanriver M, Silorane-based composite: depth of cure, surface hardness, degree of conversion, and cervical microleakage in Class II cavities, J Esthet Restor Dent 23(5) 2011, 324-35.

[10.] Marchan SM, White D, Smith WA, Raman V, Coldero L, Dhuru V. (2011), Effect of reduced exposure times on the microhardness of nanocomposites polymerized by QTH and second-generation LED curing lights, Oper Dent.36(1) 2011, 98-103.

[11.] Luis Gustavo Barrotte Albino, José Augusto Rodrigues, Yoshio Kawano, Alessandra Cassoni, Knoop microhardness and FT-Raman Evaluation of composite resins: influence of opacity and photoactivation source. Braz Oral Res 25(3) 2011, 267-73

[12.] R. B. T. Price, J. Fahey, and C. M. Felix. Knoop Microhardness Mapping Used to Compare the Efficacy of LED, QTH and PAC Curing Lights, Oper Dent.35(1) 2010, 58-68.

[13.] Ruchi Dhir Sharma, Jaideep Sharma, Arunagiri, A comparative study of degree of conversion of hybrid composite resins with nanocomposite resins when exposed to visible light cure unit and light emitting diodes : an in-vitro study, Indian Journal of Dental Sciences 2(6) 2010, 6-10

[14.] lhsan Hubbezoglu1, Giray bolayir, Orhan murat dogan, Arife dogan, Ali özer and bülent bek, Microhardness evaluation of resin composites polymerized by three different light sources. Dental Materials Journal 26(6), 2007 845-853,

[15.] Beun S, Glorieux T, Devaux J, Vreven J, Leloup G, Characterization of nanofilled compared to universal and microfilled composites, Dent Mater23(1)2007, 51-59.

[16.] Asmussen E, Peutzfeldt A, Two-step curing: influence on conversion and softening of a dental polymer, Dent Mater19(6)2003, 466470 .

[17.] Jandt KD, Mills RW, Blackwell GB, Ashworth S, Depth of cure and compressive strength of dental composites cured with blue light emitting diodes. Dental Material 16(1)2000, 41-47.

[18.] Rueggeberg FA, Caughman WF, Curtis JW JR, Davis HC, Factors affecting cure at depths within light-activated resin composites, J American Dentistry 6 (2)1993, 91-95.

[19.] Della Bonna A, PinzettaC,Rosa V, Effect of acid etching of glass ionomer cement surface on the microleakage of sandwich of restorations Journal Applied Oral Science 15(3) 2007, 230-234

[20.] Rueggeberg F. Contemporary issues in photocuring, Compend Contin Educ Dent (25) 1999, S4-S15

[21.] Soh MS, Yap AU, Siow KS, The effectiveness of cure of LED and halogen curing lights at varying cavity depths. OperDent 28(6) 2003, 707-15

[22.] Uhl A, Michaelis C, Mills RW, Jandt KD, The influence of storage and indenter load on the Knoop hardness of dental composites polymerized with LED and halogen technologies. Dent Mater20(1)2004, 21-8

[23.] Bouschlicher MR, Rueggeberg FA, Wilson BM, Correlation of bottom-to-top surface microhardness and conversion ratios for a variety of resin composite compositions. Oper Dent. 29(6)2004, 698-704

[24.] Ozel E, Korkmaz Y, Attar N, Karabulut E, Effect of one-step polishing systems on surface roughness of different flowable restorative materials. Dent Mater J. Nov 27(6) 2008, 755-64.

[25.] Leloup G, Holvoet PE, Bebelman S, Devaux J, Raman scattering determination of the depth of cure of light-activated composites: influence of different clinically relevant parameters. J Oral Rehabil.29(6) 2002, 510-5

[26.] Rueggeberg FA, Ergle JW, Mettenburg DJ, Polymerization depths of contemporary light-curing units using microhardness, J Esthet Dent. 12(6)2000, 340-9.

[27.] Yoon TH, Lee YK, Lim BS, Kim CW, Degree of polymerization of resin composites by different light sources, J Oral Rehabil 29(12) 2002, 1165-1173. 